\title{
Association between interleukin-6/6R gene polymorphisms and coronary artery disease in Russian population: influence of interleukin-6/6R gene polymorphisms on inflammatory markers
}

\author{
This article was published in the following Dove Press journal: \\ Journal of Inflammation Research \\ 3 October 2017 \\ Number of times this article has been viewed
}

\section{Vadim Mitrokhin' \\ Alexey Nikitin² \\ Olga Brovkina ${ }^{2}$ \\ Dmitry Khodyrev² \\ Alexander Zotov ${ }^{2}$ \\ Nikita Vachrushev' \\ Dmitry Dragunov 3 \\ Andrey Shim' \\ Mitko Mladenov 1,4 \\ Andre Kamkin'}

'Department of Fundamental and Applied Physiology, Russian National

Research Medical University,

${ }^{2}$ Federal Scientific Clinical Center

for Specialized Types of Medical

Assistance and Medical Technologies

for the Federal Medical and Biological

Agency, ${ }^{3}$ Scientific Research Institute

of Healthcare Organization and

Medical Management, Moscow, Russia;

${ }^{4}$ Faculty of Natural Sciences and

Mathematics, Institute of Biology,

Ss. Cyril and Methodius University,

Skopje, Macedonia
Correspondence: Mitko Mladenov Department of Fundamental and Applied Physiology, Russian National Research Medical University, Ostrovitjanova I, Moscow I I7997, Russia

Tel/fax +7 095 । 3। 4863

Email m.mitko@gmail.com

\begin{abstract}
This study determined the genotype effects of interleukin (IL)-6/IL-6R single nucleotide polymorphisms (SNPs) on circulating levels of different cytokines in healthy and coronary artery disease (CAD) patients with different allele frequencies. In the control patients, rs 1800795 showed significant differences in IL-18 concentrations between CC and CG and CC and GG genotypes ( $P=0.003$ and 0.004 , respectively). Furthermore, circulatory IL- $1 \beta$ was significantly different between $\mathrm{GC}$ and $\mathrm{GG}$ genotypes from the same $\mathrm{SNP}(P=0.038)$. In the diseased patients, significance was determined only for IL-2 $(P=0.021)$ between the $\mathrm{C}$ and $\mathrm{G}$ homozygote allele carriers of rs 1800795 . The diseased GC and GG genotype carriers were statistically different for IL-2 ( $P=0.049)$ from the rs 1800796 and for IL-4 $(P=0.049)$ from the rs2228044. IL-4 was also statistically significant between the GC and CC genotypes from the rs 2228043 of the IL-6R gene $(P=0.025)$. The last combination of genotypes in the same gene for the same SNP was statistically significant for IL-10 $(P=0.036)$. According to the logistic regression, only gender (odds ratio $[\mathrm{OR}]=2.43$ ) and triglycerides $(\mathrm{OR}=1.98)$ could be taken as determinants of CAD, while examined SNPs genotypes were not identified as risk factors for CAD. In general, the IL-6 polymorphism genotypes were mainly associated with inflammatory cytokines, while the IL-6R polymorphism genotypes were associated with anti-inflammatory cytokines.
\end{abstract}

Keywords: IL-6/IL-6R gene polymorphisms, coronary artery disease, cytokines, inflammation

\section{Introduction}

One of the major health problems severely threatening public health is coronary artery disease (CAD). The pathogenesis of CAD is associated with different factors, including hypertension, family history of atherosclerosis, obesity, diabetes mellitus, hyperlipemia, and smoking habits. ${ }^{1,2}$ Recently published studies have revealed that many inflammatory molecules play a very important role in the development of CAD. ${ }^{3-5}$ Among them, inflammatory-associated cytokines are deeply involved in the development of CAD.

Interleukin (IL)-6, as a proinflammatory cytokine, plays an important role in the pathogenesis of cardiovascular disease. ${ }^{6}$ Current data have revealed that genetic variations in the IL-6 gene and its receptor gene (IL-6R) induced different immune responses and susceptibility to $\mathrm{CAD}$. In this direction, numerous studies have examined different single nucleotide polymorphisms (SNPs) in the IL-6/IL-6R genes in relation to the susceptibility to different cardiovascular pathologies. Recent study has shown that people with developed CAD expressed different profiles of cytokines, indicating that genetic factors are important determinants of the susceptibility to CAD. ${ }^{4}$ An in vitro study has 
shown that SNPs (rs1800795 and rs1800796) in the promoter region of the IL- 6 gene are functionally very important in the susceptibility to CAD. ${ }^{7-9}$ However, recent genetic population studies are inconclusive regarding associations between the SNPs and circulating IL-6 levels. ${ }^{5,8-10}$ The reason for the discrepancies among different studies is unclear.

Based on the data mentioned earlier, we focused on the association between IL-6/IL-6R gene SNPs and their interaction with some cytokines and other CAD-associated clinical markers in a study of 198 CAD cases and 116 matched controls, within the Federal Scientific Clinical Center for Specialized Types of Medical Assistance and Medical Technologies, Moscow Cohort. Six SNPs in the IL-6 gene and five SNPs in the IL-6R gene were selected. The genotype effects of IL-6/ IL-6R SNPs on circulating levels of different cytokines in control and diseased Russian patients with different allele frequencies were determined. It was further examined as to whether CAD could interact with IL-6/IL-6R SNPs in the determination of circulating levels of other CAD-associated clinical markers.

\section{Methods}

\section{Ethical considerations}

This study was approved by the ethics committee from the Federal Scientific Clinical Center for Specialized Types of Medical Assistance and Medical Technologies (protocol no 003/2016) and conducted in accordance with the Declaration of Helsinki.

\section{Sample size}

Sample size calculation was based on district demographic data from the 2012 Census, with a population of 507,000 inhabitants. Assuming a 10\% margin of error and maximum prevalence of $50 \%$, with $95 \%$ confidence interval, a minimum sample of 126 participants (cases) was required. Considering a possible loss of $10 \%$, the final sample size was estimated at 198 participants (cases). Controls were defined according to the approximate number of cases, including 116 participants. Sample size was calculated using Statdisk Version 8.4. ${ }^{11}$

\section{Study subjects}

This study included 198 CAD and 116 control Angio-graphically characterized patients. The basic criteria for inclusion in the group with $\mathrm{CAD}$ was $\geq 50 \%$ stenosis in at least one coronary artery (left main coronary stenosis, right coronary artery, anterior descending branch, and circumflex coronary artery) and exhibiting stable or unstable angina pectoris. All analyses were conducted on patients admitted to the Federal Scientific Clinical Center for Specialized Types of Medical Assistance and Medical Technologies, Moscow. All participants in the study were from the Russian population. According to the guidelines of the Ethics Committee of the Federal Scientific Clinical Center for Specialized Types of Medical Assistance and Medical Technologies, all participants gave written informed consent containing references concerning age, gender, diabetes mellitus, hypertension, hypercholestrolemia, and smoking habits. Hypertension pertained to blood pressure $>140 / 90 \mathrm{mmHg}$ or to antihypertensive medication treatment. Diabetes mellitus was accredited to fasting glucose levels $\geq 126 \mathrm{mg} / \mathrm{dL}$, history of antidiabetic drug treatment, and/or an official diagnosis of diabetes. When the low-density lipoprotein was $\geq 3.40 \mathrm{mmol} / \mathrm{L}$, the patients were classified as hypercholesterolemic. The patients with a coronary artery bypass graft intervention, congenital heart disease, history of percutaneous coronary intervention, rheumatic valvular heart disease, severe heart failure, cardiomyopathy, end-stage renal and liver diseases, thyroid disease, malignant tumor, connective tissue disease, immune system diseases, and serious infections were excluded. The control subjects were confirmed to be free of CAD and other cardiovascular diseases, end-stage renal and liver diseases, thyroid disease, malignant tumor, immune system diseases, and serious infections. The difference between the studied groups of patients was in the presence of CAD. In actuality, both groups were composed of patients suspected of CAD, but those without determined CAD were taken as controls. In general, all patients included in the study did not take statins.

The clinical data of the control and CAD subjects, including glucose, hypertension, total cholesterol (TC), triglyceride (TG), low-density lipoprotein cholesterol (LDL-c), high-density lipoprotein cholesterol, N-terminal pro B-type natriuretic peptide (Nt-proBNP), interferon gamma (IFNgamma), bilirubin, and fibrinogen and fatty acid-binding protein (FABP), were compiled from the medical records.

\section{Blood collection}

Venous blood samples were drawn via Vacutainer plain EDTA-treated tubes from the antecubital vein after a 12 hour fast. Plasma was prepared within 1 hour at room temperature by centrifugation at $2000 \times g$ for 15 minutes. The plasma was stored at $-80^{\circ} \mathrm{C}$ until analyses were performed. For the NtproBNP determination, an electrochemical-luminescence immunoassay (pro-BNP Elec-sys; Hoffman-La Roche Ltd., Basel, Switzerland) was used. 


\section{Genotyping of IL-6 and IL-6R}

The genotype of rs 1800795 was determined using a polymerase chain reaction followed by a melting analysis of duallabeled probe. ${ }^{12,13}$ Genotyping of the remaining SNPs was carried out in real-time PCR allelic discrimination with TaqMan probes using an StepOnePlus thermal cycler (Applied Biosystems, Foster City, CA, USA). The genotype analysis of polymorphic markers of several genes was performed through endpoint fluorescence detection using the built-in tools of the SDS 2.3 software, with a sample considered positive if its quality value was $95 \%$. Samples that failed to meet this quality value were re-analyzed $(100 \%$ of samples were subjected to genotype analysis). UGENE software (Version 1.14; http://ugene.unipro.ru/) and Oligo Analyzer software (Version 1.0.3) were used for the probes and primer designs. Gene sequences were obtained from the National Center for Biotechnology (http://www.ncbi.nlm.nih.gov/). Genotype and allele frequencies were calculated via direct counting. The De-Finetti program (https://ihg.gsf.de/cgi-bin/hw/hwa1. pl) exact test was used for the estimation of the adherence of genotype distribution to the Hardy-Weinberg equilibrium. Case-control status was provided by blinded laboratory personnel, genotyping procedure validation was assured by the insertion of 26 blinded quality control samples, and blinded samples' concordance was $>99 \%$. Probes, primers, and genotyping assays are available upon request.

\section{SNP selection}

The basic criteria for SNPs inclusion in this study were their association with vascular diseases (myocardial infarction, atherosclerosis, or other peripheral vascular diseases). In cases when relationships between tagged SNPs and above noted diseases were already established in the literature, these SNPs received high priority for inclusion in the study.

The primary genes of interest were IL-6 and IL-6R. Two promoter region polymorphisms, rs 1800795 and rs 1800796 in the IL-6 gene, were primarily targeted because of their known association with the CAD, across different population studies. The investigation was expanded by searching for additional SNPs identified in the IL-6 and IL-6R genes in the database of dbSNP (http://www.ncbi.nlm.nih.gov/SNP). Nine additional SNPs were selected, including four tagging SNPs (rs2069830, rs2069842, rs2069860, and rs13306435) for IL-6 and additional five tagging SNPs (rs786205523, rs119466000, rs2228046, rs2228044, and rs2228043) for IL-6R from the same SNPs' database.
Circulating concentrations of IL- I $\beta$, IL-2, IL-4, IL-6, IL-8, IL- I8, and IL- I0 IL-1 $\beta$, IL-2, IL-4, IL-6, IL-8, IL-18, and IL-10 in plasma were analyzed by the newly developed enzyme-linked immunosorbent assay for quantitative analysis of IL-1 $\beta$, IL-2, IL-4, IL-6, IL-8, IL-18, and IL-10 levels from Bender Med-Systems. The limits of detection of the essays were $\sim 1.2 \mathrm{pg} / \mathrm{mL}$ for IL- $1 \beta$, $1.9 \mathrm{pg} / \mathrm{mL}$ for IL-2, $0.5 \mathrm{pg} / \mathrm{mL}$ for IL-4, $0.94 \mathrm{pg} / \mathrm{mL}$ for IL-6, $2.2 \mathrm{pg} / \mathrm{mL}$ for IL-8, $2.2 \mathrm{pg} / \mathrm{mL}$ for IL-18, and $1.1 \mathrm{pg} /$ $\mathrm{mL}$ for IL-10. Inter- and intraassay CVs were 6.8 and $4.7 \%$ for IL- $1 \beta, 7.4$ and $6.3 \%$ for IL-2, 9.2 and $8.6 \%$ for IL-4, 6.4 and $4.6 \%$ for IL-6, 7.8 and $6.9 \%$ for IL-8, 6.6 and $7.6 \%$ for IL-18, and 8.3 and $7.5 \%$ for IL-10, respectively.

\section{Statistical methods}

Continuous variables were expressed as mean \pm standard deviation, and categorical variables were expressed as frequencies and percentage. Normality distribution was checked for each variable. Significantly skewed variables were $\log$ transformed. Continuous variables were compared among CAD cases and controls using independent $t$-tests. The significance of differences in allele and genotype frequencies was evaluated using two-tailed Fisher's exact test with Yates's correction, followed by Bonferroni correction. Comparison of the differences between studied biomarkers among different genotypes within a particular SNP was conducted by the Mann-Whitney $U$-test. A two-tailed value of $P \leq 0.05$ was considered statistically significant. The multivariate logistic model was employed to analyze association between the studied SNPs and risk of CAD. The risk of developing CAD was calculated by determining odds ratio (OR). ${ }^{14}$ Homozygotes of the most frequent genotypes were used as a reference groups of both genes. All statistical analyses were performed using the SPSS 17.0 software (SPSS Inc., Chicago, IL, USA).

\section{Results \\ Main characteristics of the study subjects}

The baseline characteristics of the control and the group with CAD are listed in Table 1. In comparison to control, the group with CAD had a statistically appreciable variation in the gender and circulatory level of TGs. From Table 1, it is more than obvious that the baseline characteristics of the control group overlap the characteristics of the group with CAD in terms of hypertension and diabetes mellitus type II, which is plausibly the reason for such low statistical differences in all studied parameters between the two examined groups. 
Table I Baseline characteristics of the study population

\begin{tabular}{|c|c|c|c|}
\hline Variables & $\begin{array}{l}\text { Controls } \\
(n=1 \mid 6)\end{array}$ & $\begin{array}{l}\text { Patients } \\
(n=198)\end{array}$ & $P$ \\
\hline Age (years) & $74.94 \pm 7.43$ & $70.37 \pm 13.45$ & 0.648 \\
\hline Gender (M/F) & $33 / 83$ & $109 / 89$ & 0.000 \\
\hline BMI $\left(\mathrm{kg} / \mathrm{m}^{2}\right)$ & $30.33 \pm 6.09$ & $30.7 I \pm 2.75$ & 0.543 \\
\hline Smoking (yes/no) & $7 / 109$ & $1 \mathrm{I} / 187$ & 0.860 \\
\hline Hypertension (yes/no) & $63 / 53$ & $92 / 107$ & 0.144 \\
\hline Type 2 diabetes mellitus (yes/no) & $40 / 76$ & $70 / 128$ & 0.809 \\
\hline $\mathrm{TC}(\mathrm{mmol} / \mathrm{L})$ & $5.379 \pm 1.46$ & $5.22 \pm 1.27$ & 0.564 \\
\hline $\mathrm{TG}(\mathrm{mmol} / \mathrm{L})$ & $1.705 \pm 1.91$ & $1.43 \pm 0.78$ & 0.028 \\
\hline LDL-c (mmol/L) & $3.294 \pm 1.24$ & $2.94 \pm 0.93$ & 0.250 \\
\hline HDL-c (mmol/L) & $1.64 \pm 0.73$ & $1.56 \pm 0.47$ & 0.134 \\
\hline $\mathrm{CA}$ & $2.28 \pm 0.4 \mathrm{I}$ & $2.34 \pm 0.35$ & 0.331 \\
\hline
\end{tabular}

Note: $P$-values $<0.05$ are shown in bold.

Abbreviations: CA, coefficient of atherogenicity; BMI, body mass index; $F$, female; HDL-c, high-density lipoprotein cholesterol; LDL-c, low-density lipoprotein cholesterol; M, male; TC, total cholesterol; TG, triglyceride.

\section{Genotypes and allele frequencies of the IL-6 and IL-6R gene polymorphisms}

The genotype distributions for all SNPs were in the HardyWeinberg equilibrium in the control population. In the rs2069860, 109 (97.97\%) were A/A homozygotes and four (3.54\%) were $\mathrm{T} / \mathrm{T}$ homozygotes (only from the control group), while only one $(0.52 \%)$, from the group with CAD, was AT heterozygote and 10 subjects remained undetermined. The allele frequency of the A allele in the rs2069860 was 0.985 in the whole study population. In contrast, in the rs13306435, 106 (92.98\%) were $\mathrm{T} / \mathrm{T}$ homozygotes and eight $(7.02 \%)$ were A/T heterozygotes, while four subjects remained undetermined in the control group. The same SNP in the CAD group had similar genotype distribution with 192 (96.97\%) T/T homozygotes and six (3.03\%) T/A heterozygotes. The allele frequency of the $\mathrm{T}$ allele in rs 13306435 was 0.978 in the whole study population. In the healthy rs1800795, 32 (27.6\%) were G/G homozygotes, 58 (50\%) were $\mathrm{G} / \mathrm{C}$ heterozygotes, and 26 (22.4\%) were $\mathrm{C} / \mathrm{C}$ homozygotes, with a $\mathrm{G}$ allele frequency of 0.526 . The genotype distribution in the same SNP from CAD patients was 62 (31.3\%) G/G homozygotes, 100 (50.5\%) G/C heterozygotes, and $36(18.2 \%) \mathrm{C} / \mathrm{C}$ homozygotes, with a $\mathrm{G}$ allele frequency of 0.569 . The genotype distribution in rs 1800796 from the control patients was 104 (89.7\%) G/G homozygotes, 10 (8.6\%) G/C heterozygotes, and two (1.7\%) C/C homozygotes, with a $\mathrm{G}$ allele frequency of 0.939 . In the group with CAD, there was a similar distribution with $182(91.9 \%) \mathrm{G} / \mathrm{G}$ homozygotes and $16(8.1 \%) \mathrm{G} / \mathrm{C}$ heterozygotes, with a $\mathrm{G}$ allele frequency of 0.959 .

The following are the genotypes and allele frequency distribution of the IL-6R polymorphisms: in the CAD patients, rs2228044 had 156 (79.6\%) G/G homozygotes and $40(20.4 \%) \mathrm{G} / \mathrm{C}$ heterozygotes, while in the control subjects, rs2228044 had 90 (77.6\%) G/G homozygotes and $26(22.4 \%) \mathrm{G} / \mathrm{C}$ heterozygotes. The allele frequency of the $\mathrm{G}$ allele in rs2228044 was 0.887 in the control and 0.888 in the CAD subjects. In the CAD rs2228043, 154 (78.6\%) were $\mathrm{C} / \mathrm{C}$ homozygotes and 42 (21.4\%) were $\mathrm{G} / \mathrm{C}$ heterozygotes, while in the healthy subjects, $88(75.9 \%)$ were $\mathrm{C} / \mathrm{C}$ homozygotes and 28 (24.1\%) were $\mathrm{G} / \mathrm{C}$ heterozygotes. The allele frequencies of the $\mathrm{C}$ allele in rs 2228043 were 0.879 in $\mathrm{CAD}$ and 0.883 in the control group (Table 2).

In general, the control and CAD patients had a similar genotype distribution for different polymorphisms. In the control group, the genotype distribution was $35.75 \%$ for $\mathrm{C} / \mathrm{C}$, $10.1 \%$ for $\mathrm{C} / \mathrm{G}, 26.66 \%$ for $\mathrm{G} / \mathrm{G}, 8.48 \%$ for $\mathrm{A} / \mathrm{A}, 0.6 \%$ for $\mathrm{T} / \mathrm{A}$, and $17.77 \%$ for $\mathrm{T} / \mathrm{T}$. In the CAD group, the genotype distribution was $36.01 \%$ for $\mathrm{C} / \mathrm{C}, 8.97 \%$ for $\mathrm{C} / \mathrm{G}, 27.27 \%$ for $\mathrm{G} / \mathrm{G}, 8.86 \%$ for $\mathrm{A} / \mathrm{A}, 0.35 \%$ for $\mathrm{T} / \mathrm{A}$, and $17.83 \%$ for $\mathrm{T} / \mathrm{T}$. Conversely, rs2069830, rs2069842 for the IL-6 gene, and rs786205523, rs119466000, and rs2228046 for the IL-6R gene were monomorphic in the entire study population. As a result, obtained variables for these SNPs were excluded from the study.

It is worthy to notice that significant differences were observed between allele frequency and genotypes only for rs2069860 (Table 2). After the Bonferroni correction, no differences were observed at this position, probably due to the low risk obtained for these alleles.

\section{Differences between the control and patients with CAD, irrespective from their genotypes}

The IL-1 $\beta$, IL- 8 , and FABP in the group with CAD were significantly higher as compared to the control group ( $P=0.009$, 0.000 , and 0.0004 , respectively) (Table 3 ).

\section{Interaction between different genotypes within IL-6/IL-6R gene polymorphisms in relation to some inflammatory and clinical parameters associated with CAD}

The Mann-Whitney $U$-test was used in order to conduct a study for interaction between obtained genotypes for each SNPs from both different groups of patients. In the control patients, rs1800795 showed significant differences in the IL-18 concentrations between $\mathrm{C} / \mathrm{C}$ and $\mathrm{C} / \mathrm{G}$ and $\mathrm{C} / \mathrm{C}$ and $\mathrm{G} / \mathrm{G}$ genotypes $(P=0.003$ and 0.004 , respectively, Table 4$)$. Furthermore, circulatory IL- $1 \beta$ was significantly different 
Table 2 Genotype and allele frequencies of different cytokine SNPs in control and CAD patients and their association with CAD risk

\begin{tabular}{|c|c|c|c|c|c|c|c|}
\hline \multirow[t]{2}{*}{$\overline{\text { Variables }}$} & \multicolumn{2}{|c|}{ Controls } & \multicolumn{2}{|c|}{ Patients } & \multirow[t]{2}{*}{ OR $(95 \% \mathrm{Cl})$} & \multirow[t]{2}{*}{$P$} & \multirow[t]{2}{*}{$\overline{\text { pc }}$} \\
\hline & $n=116$ & $\%$ & $n=198$ & $\%$ & & & \\
\hline \multicolumn{8}{|l|}{$\overline{\text { IL-6 }}$} \\
\hline \multicolumn{8}{|c|}{ rs2069860 } \\
\hline $\mathrm{AA}$ & 109 & 96.46 & 190 & 99.48 & 1.0 & & \\
\hline AT & 0 & 0 & 1 & 0.52 & $1.72(0.069-42.73)$ & ns & ns \\
\hline TT & 4 & 3.54 & 0 & 0 & $0.064(0.0034-1.198)$ & 0.037 & ns \\
\hline \multicolumn{8}{|l|}{ Allele } \\
\hline$A$ & 218 & 96.46 & 381 & 99.74 & 1.0 & & \\
\hline $\mathrm{T}$ & 8 & 3.54 & 1 & 0.26 & $0.072(0.0089-0.576)$ & 0.004 & ns \\
\hline \multicolumn{8}{|c|}{ rs13306435 } \\
\hline $\mathrm{AA}$ & 0 & 0 & 0 & 0 & - & & \\
\hline AT & 8 & 7.02 & 6 & 3.03 & $2.42(0.82-7.15)$ & 0.18 & ns \\
\hline TT & 106 & 92.98 & 192 & 96.97 & 1.0 & & \\
\hline \multicolumn{8}{|l|}{ Allele } \\
\hline$A$ & 8 & 3.5 & 6 & 1.5 & $2.36(0.8 I-6.9)$ & 0.18 & ns \\
\hline $\mathrm{T}$ & 220 & 96.5 & 390 & 98.5 & 1.0 & & \\
\hline \multicolumn{8}{|c|}{ rsl800795 } \\
\hline GG & 32 & 27.6 & 62 & 31.3 & 1.0 & & \\
\hline GC & 58 & 50 & 100 & 50.5 & $0.89(0.52-1.52)$ & 0.77 & ns \\
\hline $\mathrm{CC}$ & 26 & 22.4 & 36 & 18.2 & $0.80(0.44-1.46)$ & 0.57 & ns \\
\hline \multicolumn{8}{|l|}{ Allele } \\
\hline G & 122 & 52.6 & 224 & 56.6 & 1.0 & & \\
\hline C & 110 & 47.4 & 172 & 43.4 & $0.85(0.62-1.18)$ & 0.38 & ns \\
\hline \multicolumn{8}{|c|}{ rsl800796 } \\
\hline GG & 104 & 89.7 & 182 & 91.9 & 1.0 & & \\
\hline GC & 10 & 8.6 & 16 & 8.1 & $0.91(0.40-2.09)$ & 0.83 & ns \\
\hline $\mathrm{CC}$ & 2 & 1.7 & 0 & 0 & $0.12(0.0055-2.92)$ & 0.34 & ns \\
\hline \multicolumn{8}{|l|}{ Allele } \\
\hline G & 228 & 93.9 & 380 & 95.9 & 1.0 & & \\
\hline C & 14 & 6.1 & 16 & 4.1 & $0.69(0.329-1.43)$ & 0.41 & ns \\
\hline \multicolumn{8}{|l|}{ IL-6R } \\
\hline \multicolumn{8}{|c|}{ rs2228044 } \\
\hline GG & 90 & 77.6 & 156 & 79.6 & 1.0 & & \\
\hline GC & 26 & 22.4 & 40 & 20.4 & $0.95(0.543-1.65)$ & 0.96 & ns \\
\hline $\mathrm{CC}$ & 0 & 0 & 0 & 0 & - & & \\
\hline \multicolumn{8}{|l|}{ Allele } \\
\hline G & 206 & 88.8 & 352 & 89.8 & 1.0 & & \\
\hline $\mathrm{C}$ & 26 & 11.2 & 40 & 10.2 & $0.90(0.53-1.52)$ & 0.79 & ns \\
\hline \multicolumn{8}{|c|}{ rs2228043 } \\
\hline GG & 0 & 0 & 0 & 0 & - & & \\
\hline GC & 28 & 24.1 & 42 & 21.4 & $1.17(0.67-2.013)$ & 0.68 & ns \\
\hline $\mathrm{CC}$ & 88 & 75.9 & 154 & 78.6 & 1.0 & & \\
\hline \multicolumn{8}{|l|}{ Allele } \\
\hline G & 28 & 12.1 & 42 & 10.7 & 1.0 & & \\
\hline C & 204 & 87.9 & 350 & 89.3 & $1.14(0.69-1.90)$ & 0.70 & ns \\
\hline
\end{tabular}

Notes: $P$-values, Fisher's exact test with Yates's correction; pc-value, after Bonferroni correction. Bold values denote $P<0.05$.

Abbreviations: CAD, coronary artery disease; Cl, confidence level; IL, interleukin; ns, nonsignificant; OR, odds ratio; SNPs, single nucleotide polymorphisms.

between $\mathrm{G} / \mathrm{C}$ and $\mathrm{G} / \mathrm{G}$ genotypes from the same SNP $(P=0.039)$. Also, IFN-gamma and Nt-proBNP showed statistically significant differences between the same genotype carriers from rs1800796 ( $P=0.013$ and 0.012 , respectively). Nt-proBNP was significantly different between $\mathrm{G} / \mathrm{C}$ and $\mathrm{G} / \mathrm{G}$ genotypes of the rs2228044 $(P=0.008)$. The same biomarker showed significant differences between $\mathrm{G} / \mathrm{C}$ and
C/C genotype carriers from the control rs2228043 IL-6R gene (Table 4). In the patients with CAD, significance was determined between $\mathrm{C}$ and $\mathrm{G}$ homozygote allele carriers of rs1800795, only for IL-2 ( $P=0.021$, Table 4). Diseased G/C and $\mathrm{G} / \mathrm{G}$ genotype carriers were statistically different for IL-2 from rs1800796 and IL-4 from rs2228044 ( $P=0.049$ and 0.030 , respectively, Table 4$)$. IL-4 was also statistically 
Table 3 Differences between the control and patients with $C A D$, irrespective of their genotypes

\begin{tabular}{ll}
\hline Control vs CAD & $\boldsymbol{P}$ \\
\hline IL-2 & 0.926 \\
IL-4 & 0.170 \\
IL-6 & 0.414 \\
IL-8 & 0.000 \\
IL-I8 & 0.371 \\
IL-I $\beta$ & 0.009 \\
IL-I0 & 0.135 \\
Bilirubin & 0.052 \\
IFN-gamma & 0.064 \\
Nt-proBNP & 0.050 \\
Myoglobin & 0.681 \\
FABP & 0.000 \\
Troponin & 0.279 \\
\hline
\end{tabular}

Note: $P$-values $<0.05$ are shown in bold.

Abbreviations: $C A D$, coronary artery disease; FABP, fibrinogen and fatty acidbinding protein; IFN-gamma, interferon gamma; IL, interleukin; $\mathrm{Nt}$-proBNP, $\mathrm{N}$-terminal pro B-type natriuretic peptide. significant between $\mathrm{G} / \mathrm{C}$ and $\mathrm{C} / \mathrm{C}$ genotypes from rs2228043 of the IL-6R gene ( $P=0.025$, Table 4$)$. The last combination of genotypes in the same gene for the same SNP was statistically significant for IL-10 ( $P=0.036$, Table 4$)$.

In general, the IL-6/IL-6R genotype/biomarker interactions within the control are completely different in comparison to interactions within the group with CAD. Basically, despite the established IL-6 interaction with other inflammatory mediators in patients with $\mathrm{CAD},{ }^{15-18}$ evidence of any association between all studied IL-6/IL-6R genotypes and circulatory IL- 6 concentration remains unconfirmed in this study.

\section{Logistic regression model for CAD}

When the baseline characteristics of the patients and the SNPs genotypes were added as covariates, logistic regression

Table 4 Interaction between different genotypes within IL-6/IL-6R gene SNPs in relation to cytokine and other CAD-associated clinical parameter concentrations in control and patients with diagnosed CAD

\begin{tabular}{|c|c|c|c|c|c|c|}
\hline \multirow{2}{*}{$\begin{array}{l}\text { Examined } \\
\text { parameters }\end{array}$} & \multicolumn{3}{|l|}{ rsI800795 } & \multirow{2}{*}{$\begin{array}{l}\text { rs|800796 } \\
G / C \sim G / G \\
P\end{array}$} & \multirow{2}{*}{$\begin{array}{l}\text { rs2228044 } \\
C / G \sim G / G \\
P\end{array}$} & \multirow{2}{*}{$\begin{array}{l}\mathrm{rs2228043} \\
\mathrm{C} / \mathrm{C} \sim \mathrm{G} / \mathrm{C} \\
P\end{array}$} \\
\hline & $\begin{array}{l}\mathbf{C} / \mathrm{C} \sim \mathrm{G} / \mathrm{C} \\
P\end{array}$ & $\begin{array}{l}\mathbf{C} / \mathbf{C} \sim \mathbf{G} / \mathbf{G} \\
P\end{array}$ & $\begin{array}{l}\mathbf{G} / \mathbf{C} \sim \mathbf{G} / \mathbf{G} \\
\mathbf{P}\end{array}$ & & & \\
\hline \multicolumn{7}{|c|}{ Control subjects } \\
\hline IL-2 & 0.261 & 0.549 & 0.278 & 0.670 & 0.324 & 0.324 \\
\hline IL-4 & 0.087 & 0.239 & 0.469 & 0.337 & 0.076 & 0.076 \\
\hline IL-6 & 0.272 & 0.083 & 0.248 & 0.456 & 0.213 & 0.213 \\
\hline IL-8 & 0.719 & 0.282 & 0.256 & 0.278 & 0.262 & 0.262 \\
\hline IL-18 & 0.003 & 0.004 & 0.500 & 0.951 & 0.390 & 0.390 \\
\hline IL-I $\beta$ & 0.443 & 0.303 & 0.039 & 0.813 & 0.339 & 0.339 \\
\hline IL-10 & 0.969 & 0.300 & 0.099 & 0.387 & 0.822 & 0.822 \\
\hline Bilirubin & 0.355 & 0.773 & 0.243 & 0.475 & 0.743 & 0.743 \\
\hline IFN-gamma & 0.489 & 0.110 & 0.054 & 0.013 & 0.083 & 0.083 \\
\hline Nt-proBNP & 0.835 & 0.754 & 0.987 & 0.012 & 0.008 & 0.008 \\
\hline Myoglobin & 0.660 & 0.384 & 0.672 & 0.582 & 0.594 & 0.594 \\
\hline FABP & 0.489 & 0.513 & 0.920 & 0.055 & 0.614 & 0.614 \\
\hline \multirow[t]{4}{*}{ Troponin } & 0.479 & 0.303 & 0.393 & 0.287 & $0.28 I$ & 0.281 \\
\hline & rsI800795 & rs1800796 & rs2228044 & rs2228043 & & \\
\hline & $\overline{\mathbf{C} / \mathbf{C} \sim \mathbf{G} / \mathbf{G}}$ & $\mathbf{G} / \mathbf{C} \sim \mathbf{G} / \mathbf{G}$ & $\mathbf{C} / \mathbf{G} \sim \mathbf{G} / \mathbf{G}$ & $\mathbf{C} / \mathbf{C} \sim \mathbf{G} / \mathbf{C}$ & & \\
\hline & $P$ & $P$ & $P$ & $P$ & & \\
\hline \multicolumn{7}{|c|}{ Patients with diagnosed CAD } \\
\hline IL-2 & 0.021 & 0.049 & 0.516 & 0.696 & & \\
\hline IL-4 & 0.251 & 0.706 & 0.030 & 0.025 & & \\
\hline IL-6 & 0.067 & 0.949 & 0.250 & 0.182 & & \\
\hline IL-8 & 0.624 & 0.114 & 0.850 & 0.558 & & \\
\hline IL-18 & 0.804 & 0.888 & 0.440 & 0.519 & & \\
\hline IL-I $\beta$ & 0.717 & 0.508 & 0.736 & 0.636 & & \\
\hline IL-I0 & 0.398 & 0.760 & 0.051 & 0.036 & & \\
\hline Bilirubin & 0.126 & 0.679 & 0.131 & 0.105 & & \\
\hline IFN-gamma & 0.514 & 0.734 & 0.432 & 0.577 & & \\
\hline Nt-proBNP & 0.739 & 0.647 & $0.28 I$ & 0.243 & & \\
\hline Myoglobin & 0.286 & 0.532 & 0.282 & 0.808 & & \\
\hline FABP & 0.343 & $0.64 I$ & 0.921 & 0.525 & & \\
\hline Troponin & 0.152 & 0.432 & 0.264 & 0.475 & & \\
\hline
\end{tabular}

Note: $P$-values $<0.05$ are shown in bold.

Abbreviations: CAD, coronary artery disease; FABP, fibrinogen and fatty acid-binding protein; IFN gamma, interferon gamma; IL, interleukin; Nt-proBNP, N-terminal pro B-type natriuretic peptide; SNPs, single nucleotide polymorphisms. 
Table 5 Logistic regression analysis for patients with CAD

\begin{tabular}{lll}
\hline Variables & $\mathbf{P}$ & OR (\% 95 Cl) \\
\hline Gender & $\mathbf{0 . 0 1 8}$ & $1.91(1.16-2.98)$ \\
TG & $\mathbf{0 . 0 2 6}$ & $2.57(1.11-3.52)$ \\
\hline
\end{tabular}

Note: $P$-values $<0.05$ are shown in bold.

Abbreviations: $\mathrm{CAD}$, coronary artery disease; $\mathrm{Cl}$, confidence interval; $\mathrm{OR}$, odds ratio; TG, triglyceride.

revealed only gender $(\mathrm{OR}=1.91)$ and high $\mathrm{TGs}(\mathrm{OR}=2.57)$ to be the strongest determinants of CAD (Table 5).

\section{Discussion}

The development of molecular biology techniques has allowed identification of the genetic polymorphisms within regulatory regions of cytokine genes and confirmed the finding that the level of cytokine production differs among individuals. These considerations have prompted many authors to investigate the regulation of genes expressing these cytokines in relation to susceptibility to CAD. There is an increasing number of studies devoted to this topic in the recent literature. However, to date, there are no studies conducted in Russian Federation that address this issue.

The present discussion has been based on the data considered significant as compared with those obtained from similar studies. These findings may suggest that different settings may be regulated by different cytokine production pathways and that IL-6 together with IL-6R has a biological role in susceptibility to CAD. It is also known that the balance between pro-inflammatory and anti-inflammatory markers has a critical role in the development of CAD. ${ }^{19-21}$ In this direction, different sets of epidemiological studies have revealed that specific SNPs in different genes, such as IL-6, IL-16, IL-17, IL-18, and IL-23, are associated with the development of CAD. ${ }^{22-28}$ The results from this research, regarding T allele from rs 2069860 , associated with the patients without CAD, suggest that rs2069860 is typical for the development of hypertension or diabetes mellitus type II but not for CAD. Other studies have reported association between rs 1800795 and rs1800796 and the risk of CAD. ${ }^{29-31}$ In the Korean population, an association between the rs 1800795 genotype and CAD was also confirmed..$^{29}$ Phulukdaree et al ${ }^{30}$ reported the rs $1800795 \mathrm{G}$ allele association with the increased risk of CAD development in South African Indians. In a metaanalysis study conducted by Yang et $\mathrm{a}^{32}$ including an additional 19 studies, rs 1800795 and rs 1800796 were associated with the increased risk of CAD. Conversely, some other studies found inconsistent results. In a case-control study of the Chinese population, no association was found between rs1800795 and rs1800796 SNPs regarding the risk of CAD, ${ }^{31}$ which is in agreement with the results from this study. Actually, no association was found between CAD and all tagged SNPs. We are of an opinion that such an inconsistency is probably a result of the group selection. It seems that there is an overlap between baseline characteristics of the patients without and with CAD. In fact, the percentage of distribution of diabetes mellitus type II and hypertension is similar in both studied groups. In addition, one population study ${ }^{33}$ has found relationships between hypertension, diabetes mellitus type II, specific SNPs, and susceptibility to CAD. In addition, the advanced age of the subjects from both groups in this study can be taken as another reason for an unexpected distribution of the studied SNPs. The association between IL-6/IL-6R SNPs and different circulating cytokines was another aim of this study. The absolute differences in the IL-1 $\beta$, IL-8, and FABP means in the group with CAD were significantly higher as compared to the control group. Therefore, the higher concentrations of the IL- $1 \beta$, IL- 8 , and FABP in the patients with CAD could be taken as a common inflammatory initiator in the process of the development of CAD. Certainly, partial roles of particular genotypes from all tagged SNPs in such a complex mechanism could be determined, but because of the huge discrepancies in the distribution of the studied genotypes, this analysis was eliminated from the investigation. These discrepancies could be the result of environmental and other differences associated with the clinical sample, gender, disease status, aging, and so on. For instance, in the Caucasian or Western population, rs $1800796 \mathrm{C}$ allele was associated with increased IL-6 level..$^{33}$ Correspondingly, such an association was not the case between rs $1800796 \mathrm{GC}$ genotype and circulating IL-6 level in hypercholesterolemic and patients with myocardial infarction. ${ }^{34,35}$ IL-6 rs 1800795 SNP significantly affected the plasma IL-18 levels as they were higher in the risk allele C carriers of this SNP. Since this is a promoter region polymorphism, certain researchers suggest that it might directly affect the transcription regulation factors (activators) leading to altered production of IL- $6,{ }^{36}$ or that it might be tagging a gene variant affecting the transcriptional regulation of IL-18 production. ${ }^{37}$ In the control subjects from this study, rs $1800795 \mathrm{C} / \mathrm{C}$ genotypes were associated with significantly higher circulating levels of IL-18 than the $\mathrm{G} / \mathrm{C}$ or $\mathrm{G} / \mathrm{G}$ genotypes. This is in support of the exaggerated $\mathrm{C} / \mathrm{C}$ raising effect during inflammation. Correspondingly, similar exaggeration was determined for the G/G genotype in the same SNP, expressed through IL-1 $\beta$ ( $P=0.039$, Table 4$)$. These associations between some proinflammatory cytokines with some genotypes in the control subjects from this study are probably based on the widespread 
hypertension and diabetic disease in the group without CAD. In point of fact, in patients with $\mathrm{CAD}$, such differences were not seen, possibly because of the worsened inflammatory situation in genotypes from all the studied SNPs. Theoretically, it seems that in the case with proinflammatory cytokines, similar disease-genotype interactions lie in the basis of the different clinical settings, specific for hypertension, diabetes mellitus, and CAD.

Also, rs1800795 $\mathrm{G}$ allele exerted an influence on the IFN-gamma and Nt-proBNP in the subjects without CAD. Similar influences on Nt-proBNP had G/G genotype from rs2228044 carriers. Conversely, increased Nt-proBNP in the control rs2228043 was specific for the $\mathrm{C} / \mathrm{C}$ genotype. As described previously, detected association between circulatory Nt-proBNP, IFN-gamma, and some specific genotypes could be prescribed of the specificity of the clinical sample.

Furthermore, CAD individuals that were homozygous for $\mathrm{G}$ allele produced significantly higher amount of IL-2 than $\mathrm{C} / \mathrm{C}$ and $\mathrm{G} / \mathrm{C}$ genotypes. In the present study, we observed significant differences in the frequency of the $\mathrm{C} / \mathrm{C}$ and $\mathrm{G} / \mathrm{C}$ genotypes, which are associated with low IL-2 production. The mechanism by which this is accomplished is currently under study. It is possible that the GG genotype from both polymorphisms rs1800795 and rs1800796 (Table 4), interferes with the binding of a key silencer element, thereby resulting in enhanced (or not) IL-2 production in patients with CAD. In addition, increased IL-4 was associated with GG and CC genotypes in rs2228043 and rs2228044, respectively. This study also shows that IL-10 levels in subjects without CAD are influenced by IL-6R gene variants including rs2228043, as they were higher in the risk allele C carriers of this SNP. This is probably a result of the suppression of IL-10 production via activation of the STAT group of transcription regulation factors (repressors) by the IL-10 gene variant. ${ }^{38}$ It is interesting to note that, in the patients with $\mathrm{CAD}$, anti-inflammatory response was more pronounced in comparison to the controls. Taking into account the study of Scheller et al, ${ }^{39}$ it seems that IL-6R association with increased IL-4 and IL-10 in patients with CAD lies in the basis of the anti-inflammatory or even regenerative activities of IL-6R, mediated by its classic signaling (stimulation via a membrane bound IL-6R). ${ }^{39}$

Beside the abovementioned association between SNPs and different cytokines in patients with CAD, Holvoet et $\mathrm{al}^{40}$ reported that oxi-LDL is associated with sub-clinical and clinical CAD onset in different ethnic groups. In this theory, a positive association was found between increased TG and
CAD (confirmed by the logistic regression model). The pivotal role of TG in lipid metabolism is not directly atherogenic but TG is taken as an important marker of CAD risk because of its association with atherogenic remnant particles. ${ }^{41,42}$

In conclusion, by examining the inflammatory and antiinflammatory cytokines, this study revealed that IL-1 $\beta$, IL-18, IL-4, and IL-10 as significantly changed cytokines are associated with different SNPs in patients with CAD. However, different gene variants may be tagging the functional SNPs in the transcriptional regulatory regions or gene promoter region of inflammatory or immune biomarkers involved in the pathogenesis of CAD. ${ }^{43}$ The carriage of the particular risk alleles might further increase transcriptional activity enhancing the proinflammatory status. In future studies, nearest gene annotation can be useful to differentiate between the actual causal variant and the tagging SNP.

\section{Limitations}

One of the major limitation of this study pertains to the fact that only a total of 11 genetic variants were reported. This study was performed in order to evaluate the interaction of different SNP genotypes with CAD in association with pro and anti-inflammatory cytokines. The cross-sectional nature of the study was one of its basic limitations. The prospective prediction of the IL-6/IL6R genotypes effects upon the development of CAD is impossible at this stage. Another limitation was the sample size, owing to the exclusion of patients with mild CAD $(<50 \%$ stenosis in one or more epicardial vessels).

In addition, the participants with suspicious clinical characteristics were excluded from the study.

The strength of this study is in its homogeneous population, consisting of patients at the same age from the same race and nationality.

\section{Acknowledgments}

This research was supported by a grant from the Federal Scientific Clinical Center for Specialized Types of Medical Assistance and Medical Technologies for the Federal Medical and Biological Agency, Moscow Russia. The authors want to express special thanks to the medical expert, Dr. Roman Ovchinnikov, for data collection.

\section{Author contributions}

All authors contributed to data analysis, drafting and critically revising the paper and agree to be accountable for all aspects of the work. 


\section{Disclosure}

The authors report no conflicts of interest in this work.

\section{References}

1. Zidi W, Allal-Elasmi M, Zayani Y, et al. Metabolic syndrome, independent predictor for coronary artery disease. Clin Lab. 2015;61(10): $1545-1552$.

2. Duval S, Long HK, Roy SS, et al. The contribution of tobacco use to high health care utilization and medical costs in peripheral artery disease: a state-based cohort analysis. JAm Coll Cardiol. 2015;66(14):1566-1574.

3. Wang JB, Liu J, Geng J, Zhang Q, Hu TT, Xu B. Association between three interleukin-10 gene polymorphisms and coronary artery disease risk: a meta-analysis. Int J Clin Exp Med. 2015;8(10):17842-11755.

4. Zhang LL, Wang QY, Fu B, Zhao LS, Kui Y. Aldehyde dehydrogenase 2 (ALDH2) polymorphism gene and coronary artery disease risk: a meta-analysis. Genet Mol Res. 2015;14(4):18503-18514.

5. Goodarzynejad H, Boroumand M, Behmanesh M, Ziaee S, Jalali A. Cholesteryl ester transfer protein gene polymorphism (I405V) and premature coronary artery disease in an Iranian population. Bosn $J$ Basic Med Sci. 2016;16(2):114-120.

6. Cheng OT. Rising incidence of coronary artery disease in China in parallel with rising 'normal' plasma cholesterol levels. Atherosclerosis. 2004;173(2):371.

7. Song JH, Zhou HX, Guo L, Tian LF, Guo FX, Sun XY. Association of phosphodiesterase $4 \mathrm{D}$ gene and interleukin- 6 receptor gene polymorphisms with ischemic stroke in a Chinese hypertensive population. Genet Mol Res. 2015;14(4):19396-19403.

8. Yan L, Hu R, Tu S, et al. Meta-analysis of association between IL6-634C/G polymorphism and osteoporosis. Genet Mol Res. 2015;14(4): 19225-19232.

9. Ma H, Sun G, Wang W, et al. Association between Interleukin-6-572 $\mathrm{C}>\mathrm{G}$ and $-174 \mathrm{G}>\mathrm{C}$ polymorphisms and hypertension: a meta-analysis of case control studies. Medicine (Baltimore). 2016;95(2):e2416.

10. Elsaid A, Abdel-Aziz FA, Elmougy R, Elwaseef MA. Association of polymorphisms G (174) C in IL-6 gene and G (-1082) A in IL-10 gene with traditional cardiovascular risk factors in patients with coronary artery disease. Indian J Biochem Biophys. 2014;51(4):282-292.

11. Triola MF. Statdisk (Version 8.4) for Elementary Statistics. Rio de Janeiro: LTC; 2003:410.

12. Housni EH, Heimann P, Parma J, Vassart G. Single-nucleotide polymorphism genotyping by melting analysis of dual-labeled probes: examples using factor V Leiden and prothrombin 20210A mutations. Clin Chem. 2003;49(10):1669-1672.

13. Shadrina A, Voronina E, Zolotukhin I, Filipenko M. Allele and genotype frequencies of polymorphisms in cytokine genes in ethnic Russian individuals from Moscow, Russia. Hum Immunol. 2017;78(2):190-191.

14. Guo SW, Thompson EA. A Monte Carlo method for combined segregation and linkage analysis. Am J Hum Genet. 1992;51(5):1111-1126.

15. Mitrokhin MV, Mladenov IM, Kamkin GA. Effects of interleukin-6 on the bio-electric activity of rat atrial tissue under normal conditions and during gradual stretching. Immunobiology. 2015;220(9):1107-1112.

16. Mitrokhin MV, Mladenov IM, Kamkin GA. IL-1 provokes electrical abnormalities in rat atrial myocardium. Int Immunopharmacol. 2015;28(1):780-784.

17. Mitrokhin MV, Shim LA, Aksyonov AA, et al. Circulating interleukin-18: association with IL-8, IL-10 and VEGF serum levels in patients with and without heart rhythm disorders. Int J Cardiol. 2016;215:105-109.

18. Shim LA, Aksyonov AA, Mitrokhin MV, et al. Serum interleukin-6: association with circulating cytokine serum levels in patients with sinus arrhythmia and patients with coronary artery disease. Cell Immunol. 2016;310:178-183.

19. Belenkova Y, Karetnikova V, Diachenko A, et al. Association of inflammatory markers and poor outcome in diabetic patients presenting with ST segment elevation myocardial infarction. J Inflamm Res. 2015;8:107-116.
20. Mouridsen MR, Nielsen OW, Carlsen CM, et al. High-sensitivity C-reactive protein and exercise-induced changes in subjects suspected of coronary artery disease. J Inflamm Res. 2014;7:45-55.

21. Chen Y, Zhong M, Liang L, Gu F, Peng H. Interleukin-17 induces angiogenesis in human choroidal endothelial cells in vitro. Invest Ophthalmol Vis Sci. 2014;55(10):6968-6975.

22. Zhang M, Cai RZ, Zhang B, et al. Functional polymorphisms in interleukin-23 receptor and susceptibility to coronary artery disease. DNA Cell Biol. 2014;33(12):891-897.

23. Zhang X, Pei F, Zhang M, et al. Interleukin-17A gene variants and risk of coronary artery disease: a large angiography-based study. Clin Chim Acta. 2011;412(3-4):327-331.

24. Huang H, Zeng Z, Zhang L, et al. The association of interleukin-16 gene polymorphisms with susceptibility of coronary artery disease. Clin Biochem. 2013;46(3):241-244.

25. Opstad BT, Pettersen AA, Arnesen H, Seljeflot I. Circulating levels of IL-18 are significantly influenced by the IL- $18+183 \mathrm{~A} / \mathrm{G}$ polymorphism in coronary artery disease patients with diabetes type 2 and the metabolic syndrome: an observational study. Cardiovasc Diabetol. 2011; 10:110.

26. Opstad BT, Arnesen H, Pettersen AA, Seljeflot I. The MMP-9-1562 C/T polymorphism in the presence of metabolic syndrome increases the risk of clinical events in patients with coronary artery disease. PLoS One. 2014;9(9):e106816.

27. Galimudi KR, Spurthi KM, Padala C, et al. Interleukin 6(-174G/C) variant and its circulating levels in coronary artery disease patients and their first degree relatives. Inflammation. 2014;37(2):314-321.

28. He F, Teng X, Gu H, et al. Interleukin-6 receptor rs 7529229 T/C polymorphism is associated with left main coronary artery disease phenotype in a Chinese population. Int J Mol Sci. 2014;15(4):5623-5633.

29. Jang Y, Kim YO, Hyun JY, et al. Interleukin-6-572C $>$ G polymorphismassociation with inflammatory variables in Korean men with coronary artery disease. Transl Res. 2008;151(3):154-161.

30. Phulukdaree A, Khan S, Ramkaran P, Govender R, Moodley D, Chuturgoon AA. The interleukin- $6-147 \mathrm{~g} / \mathrm{c}$ polymorphism is associated with increased risk of coronary artery disease in young South African Indian men. Metab Syndr Relat Disord. 2013;11(3):205-209.

31. Tong Z, Li Q, Zhang J, Wei Y, Miao G, Yang X. Association between interleukin 6 and interleukin 16 gene polymorphisms and coronary heart disease risk in a Chinese population. J Int Med Res. 2013;41(4): 1049-1056.

32. Yang Y, Zhang F, Skrip L, et al. IL-6 gene polymorphisms and CAD risk: a meta-analysis. Mol Biol Rep. 2013;40(3):2589-2598.

33. Ma X, Bai G, Lu D, et al. Association between STK11 gene polymorphisms and coronary artery disease in type 2 diabetes in Han Population in China. J Diabetes Res. 2017;2017:6297087.

34. Brull JD, Montgomery EH, Sanders J, et al. Interleukin-6 gene -174G $>\mathrm{C}$ and $-572 \mathrm{G}>\mathrm{C}$ promoter polymorphisms are strong predictors of plasma interleukin-6 levels after coronary artery bypass surgery. Arterioscler Thromb Vasc Biol. 2001;21(9):1458-1463.

35. Bennermo M, Held C, Green F, et al. Prognostic value of plasma interleukin- 6 concentrations and the $-174 \mathrm{G}>\mathrm{C}$ and $-572 \mathrm{G}>\mathrm{C}$ promoter polymorphisms of the interleukin- 6 gene in patients with acute myocardial infarction treated with thrombolysis. Atherosclerosis. 2004;174(1):157-163.

36. Satti HS, Hussain S, Javed Q. Association of interleukin-6 gene promoter polymorphism with Coronary Artery Disease in Pakistani families. Scientific WorldJournal. 2013;2013:538365.

37. Matteini AM, Li J, Lange EM, et al. Novel gene variants predict serum levels of the cytokines IL18 and IL-1ra in older adults. Cytokine. 2014;65(1): $10-16$.

38. Kahraman A, Cakar H, Koken T. The protective effect of quercetin on long-term alcohol consumption-induced oxidative stress. Mol Biol Rep. 2012;39(3):2789-2794.

39. Scheller J, Chalaris A, Schmidt-Arras D, Rose-John S. The pro- and anti-inflammatory properties of the cytokine interleukin-6. Biochim Biophys Acta. 2011;1813(5):878-888. 
40. Holvoet P, Jenny SN, Schreiner JP, Tracy PR, Jacobs RD. Multi-Ethnic study of atherosclerosis. The relationship between oxidized LDL and other cardiovascular risk factors and subclinical CVD in different ethnic groups: the multi-ethnic study of Atherosclerosis (MESA). Atherosclerosis. 2007;194(1):245-252.

41. McLarty JL, Li J, Levick SP, Janicki JS. Estrogen modulates the influence of cardiac inflammatory cells on function of cardiac fibroblasts. J Inflamm Res. 2013;6:99-108.
42. Miller M, Stone JN, Ballantyne C, et al. Triglycerides and cardiovascular disease: a scientific statement from the American Heart Association. Circulation. 2011;123(20):2292-2333.

43. Bhushan S, Perumal NB. Disease associated cytokine SNPs database: an annotation and dissemination model. Cytokine. 2012;57(1): $107-112$.

\section{Publish your work in this journal}

The Journal of Inflammation Research is an international, peer-reviewed open access journal that welcomes laboratory and clinical findings on the molecular basis, cell biology and pharmacology of inflammation including original research, reviews, symposium reports, hypothesis formation and commentaries on: acute/chronic inflammation; mediators of
Dovepress

inflammation; cellular processes; molecular mechanisms; pharmacology and novel anti-inflammatory drugs; clinical conditions involving inflammation. The manuscript management system is completely online and includes a very quick and fair peer-review system. Visit http://www.dove press.com/testimonials.php to read real quotes from published authors. 